University of Nebraska - Lincoln

DigitalCommons@University of Nebraska - Lincoln

USDA Wildlife Services - Staff Publications

U.S. Department of Agriculture: Animal and Plant Health Inspection Service

November 2007

\title{
Anti-prion activity generated by a novel vaccine formulation
}

John Pilon

USDA APHIS WS National Wildlife Research Center

Christina Loiacono

USDA APHIS National Veterinary Services Laboratories, Ames, IA

Danelle Okeson

USDA APHIS WS National Wildlife Research Center

Sharon Lund

USDA APHIS WS National Wildlife Research Center

Kurt C. Vercauteren

USDA-APHIS-Wildlife Services, kurt.c.vercauteren@usda.gov

See next page for additional authors

Follow this and additional works at: https://digitalcommons.unl.edu/icwdm_usdanwrc

Part of the Environmental Sciences Commons

Pilon, John; Loiacono, Christina; Okeson, Danelle; Lund, Sharon; Vercauteren, Kurt C.; Rhyan, Jack; and Miller, Lowell, "Anti-prion activity generated by a novel vaccine formulation" (2007). USDA Wildlife Services - Staff Publications. 770.

https://digitalcommons.unl.edu/icwdm_usdanwrc/770

This Article is brought to you for free and open access by the U.S. Department of Agriculture: Animal and Plant Health Inspection Service at DigitalCommons@University of Nebraska - Lincoln. It has been accepted for inclusion in USDA Wildlife Services - Staff Publications by an authorized administrator of DigitalCommons@University of Nebraska - Lincoln. 


\section{Authors}

John Pilon, Christina Loiacono, Danelle Okeson, Sharon Lund, Kurt C. Vercauteren, Jack Rhyan, and Lowell Miller 


\title{
Anti-prion activity generated by a novel vaccine formulation ${ }^{\text {is }}$
}

\author{
John Pilon ${ }^{\mathrm{a}, *}$, Christina Loiacono ${ }^{\mathrm{b}}$, Danelle Okeson ${ }^{\mathrm{a}, 1}$, Sharon Lund ${ }^{\mathrm{b}}$, \\ Kurt Vercauteren ${ }^{\mathrm{a}}$, Jack Rhyan ${ }^{\mathrm{c}}$, Lowell Miller ${ }^{\mathrm{a}}$ \\ a USDA APHIS WS National Wildlife Research Center, Fort Collins, CO 80521, USA \\ ${ }^{\mathrm{b}}$ USDA APHIS National Veterinary Services Laboratories, Ames, IA 50010, USA \\ ${ }^{c}$ USDA APHIS VS National Wildlife Research Center, Fort Collins, CO 80521, USA
}

Received 24 July 2007; accepted 7 October 2007

\begin{abstract}
Chronic wasting disease (CWD) is a transmissible spongiform encephalopathy (TSE) of domestic and wild cervids in North America. To address possible prevention regimens for CWD, we have used a mouse model system and the Rocky Mountain Laboratory (RML) mouse-adapted scrapie prion strain to screen efficacy of potential vaccine candidates. Three peptides derived from the primary amino acid sequence of the prion protein were conjugated to blue carrier protein (BCP) and formulated in an adjuvant containing $M$. avium subsp. avium. CL57/BL6 mice were vaccinated and boosted with $50 \mu \mathrm{g}$ of the carrier protein-peptide conjugate formulation; all vaccines produced a humoral immune response as measured by ELISA. Disease challenge with the RML scrapie prion strain revealed anti-prion activity was generated by the vaccine formulations as measured by a delay in clinical disease onset and prolonged survivorship.
\end{abstract}

(C) 2007 Elsevier Ireland Ltd. All rights reserved.

Keywords: Prion; Chronic wasting disease (CWD); Transmissible spongiform encephalopathy (TSE); Scrapie; Vaccine

The unique self-protein nature of the transmissible spongiform encephalopathy (TSE) infectious agent, the prion, presents a major obstacle in the development of an effective vaccine to prevent these invariably fatal neurodegenerative diseases. A large body of scientific evidence has revealed that a key event in the transmission and propagation of TSE diseases is the formation of a proteinase $\mathrm{K}(\mathrm{PK})$ resistant prion (denoted here as $\mathrm{PrP}^{\mathrm{res}}$ ) from the normal $\mathrm{PK}$ sensitive cellular form $\left(\operatorname{PrP}^{\mathrm{c}}\right)$. The transformation from a non-pathogenic protein to the pathogenic form occurs due to a post-translational protein refolding event that changes $\operatorname{PrP}^{\mathrm{c}}$ from a protein that has high $\alpha$-helical content to one that has high $\beta$-sheet content [9]. The refolding process can occur spontaneously, as with sporadic Cruezfledt Jakob disease (sCJD), or due to either a templating or seeding mechanism whereby normal $\mathrm{PrP}^{\mathrm{c}}$ adopts a new conformation in the presence of the incorrectly folded $\operatorname{PrP}^{\text {res }}[1]$.

\footnotetext{
Disclaimer: Mention of companies or commercial products does not imply recommendation or endorsement by the USDA. Product names are mentioned solely to report factually on available data and to provide specific information.

* Corresponding author. Tel.: +1 970266 6141; fax: +1 9702666157.

E-mail address: john.l.pilon@ aphis.usda.gov (J. Pilon).

${ }^{1}$ Present address: San Antonio Zoo, San Antonio, TX 78209, USA.
}

When considering the entire TSE disease family, only the cervid specific chronic wasting disease (CWD) and sheep scrapie are readily transmissible to susceptible hosts through horizontal transmission of infected animals or environmental reservoirs of infectivity [6-8]. To develop a CWD management tool, we have evaluated peptide-based vaccine candidates for eventual use in farmed and wild cervids. As an initial step towards a CWD vaccine we selected a murine-based model, the Rocky Mountain Laboratory (RML) mouse-adapted scrapie prion strain, and peptides from regions of the prion protein that are implicated in playing a role in $\mathrm{PrP}^{\mathrm{c}}$ to $\mathrm{PrP}^{\mathrm{res}}$ conversion.

Peptides from the primary amino acid sequence of the prion protein were used that span the following regions; peptide 2, 112-AGAAAAGAVVGGKGGYMLGSAMSRPMMHFG-141, peptide 4, 165-VDQYNNQNNFVHDC-178, and peptide 6, 141-GNDWEDRYYRENMYRYPNQ-159 160. Peptides were synthesized by standard Fmoc strategies by Global Peptide Services, Fort Collins, CO, USA. All peptides were $>90 \%$ pure as demonstrated by high-performance liquid chromatography. All peptides, except peptide 4, were synthesized with either an $\mathrm{N}$-terminal or $\mathrm{C}$-terminal linker containing a glycine cystine for conjugation to blue carrier protein (BCP) (BioSonda Santiago, Chile) using standard sulfosuccimnimidyl $4-(\mathrm{N}-$ 
Table 1

Survival statistics

\begin{tabular}{lllllll}
\hline Group & Total animals & Survival range & Mean \pm S.D. & Survival median & Mann-Whitney vs. Adjuvac & Mann-Whitney vs. positive control \\
\hline Adjuvac $^{\mathrm{TM}}$ & 14 & $172-221$ & $206 \pm 14$ & 210 & & \\
Positive & 14 & $203-231$ & $214 \pm 8$ & 215 & .1543 & .0008 \\
Vaccine 2 & 14 & $203-236$ & $219 \pm 8$ & 219 & .0041 & .0008 \\
Vaccine 4 & 11 & $211-248$ & $232 \pm 12$ & 235 & .0002 & .056 \\
Vaccine 6 & 14 & $198-254$ & $228 \pm 19$ & 231 & .0076 & \\
\hline
\end{tabular}

maleimidomethyl) cycloheaxane-1-carboxylate (Sulfo-SMCC, Pierce, Rockford, IL, USA) technology. Peptides 2 and 4 are known to prevent the conversion of $\operatorname{PrP}^{\mathrm{c}}$ to $\operatorname{Pr}^{\mathrm{res}}$ in in vitro conversion reactions $[2,4]$. The prion sequence of peptide 6 was chosen based on work by White et al. that demonstrated administration of monoclonal antibodies with affinity to the 143-159 region of $\operatorname{PrP}^{\mathrm{c}}$ increased survivorship of RML scrapie challenged mice from 150 days to $>500$ days [14].

Blue carrier protein was selected over the traditional Keyhole Limpet Hemocyanin (KLH) due to its reported improved stability, high molecular weight, and enhanced immunogenicity [3]. All vaccine conjugates were made into a water in oil emulsion using the adjuvant Adjuvac ${ }^{\mathrm{TM}}$, developed at the National Wildlife Research Center. Adjuvac ${ }^{\mathrm{TM}}$ is a modification of the Johne's disease vaccine Mycopar ${ }^{\mathrm{TM}}$, containing $M$. avium subsp. avium, (Fort Dodge Animal Health, Fort Dodge, IA, USA).

Animal procedures were approved by the Institutional Animal Care and Use Committee of the USDA APHIS Wildlife Services', National Wildlife Research Center to assure all efforts were made to minimize animal pain and discomfort during the course of this study. C57/BL6 female mice were (Hilltop Labs, Scottsdale, AZ, USA) assigned at random into three vaccine treatment groups, one negative control group and two positive control groups. One positive control group received only disease challenge; the second received both disease challenge and the vaccine adjuvant (Adjuvac $\left.{ }^{\mathrm{TM}}\right)$. Treatment animals received two doses of vaccine $(50 \mu \mathrm{g}$ of conjugate-carrier protein in both the prime and boost vaccinations) 32 days apart via intramuscular injection in a hind leg. Fifteen days after the booster injections animals were challenged via intraperitoneal injection with $50 \mu 1$ of RML scrapie brain homogenate, graciously provided by Rocky Mountain Laboratories (Hamilton MT, USA), diluted in PBS to a final concentration of $1 / 100$ $(w / v)$. All animals demonstrated well-characterized signs of clinical mouse-adapted scrapie at the time of sacrifice as indicated by; lethargy, hyperactivity, polydipsia, ataxia, kyphosis (hunched back), poor coat condition, and wasting. To confirm TSE diagnosis and pathology of end-stage clinical animals, one animal per group was selected for immuno-histochemistry (IHC) analysis and at least two animals were selected for Western blot.

Five mice per group were selected for blood collection to monitor the production of antibodies towards the vaccine regimen by ELISA. To measure humoral immune response all vaccine peptides were conjugated to maleimide activated bovine serum albumin (BSA) (Pierce). Titers were defined as the maxi- mal dilution at which the absorbance reading is two fold higher than a typical background reading (0.070).

All vaccine constructs induced a humoral response. ELISA results show a relatively strong immune response to vaccines, 2 , 4, and 6 (Fig. 1). Linear regression analysis of humoral response and median days until sacrifice shows no correlation between antibody levels and length of time until sacrifice $\left(R^{2}=0.369\right)$. Indeed, vaccine 4 prolonged survivorship by 20 days relative to the positive control, more than any of the vaccine constructs studied, but had the lowest measured titer. Vaccine 6 showed the highest titers of all vaccines tested with titers measured by peptide ELISAs of 1/25,000 12 days after the first prime vaccination (data not shown). Titers after both prime and boost vaccinations were determined to be: Vaccine $2=1 / 32,000$; vaccine $4=1 / 10,000$; vaccine $6=1 / 40,000$.

All vaccines improved the median of days to sacrifice relative to both the positive control groups. Application of the nonparametric Mann-Whitney $U$-test to evaluate the null hypothesis between the positive control groups and the vaccinate groups demonstrated that vaccine 4 was the most successful, with vaccines 6 and 2 also showing significance at the $95 \%$ confidence interval. The results of the statistical analysis are shown in Table 1 . The $p$ value for all treatment groups increased when vaccinates are compared with the positive control animals that received only the RML scrapie challenge. Assessment of the observed anti-PrP ${ }^{\mathrm{res}}$ protection based purely on the median days until sacrifice and Kaplan-Meier survivor curves shown in Fig. 2 would suggest that vaccines 4 and 6 provided the highest degree of protection against disease progression. Indeed, a comparison of the 25 and 21 days increase in median days to sacrifice for vaccines 4 and 6, respectively correlates to a reduction in infectious

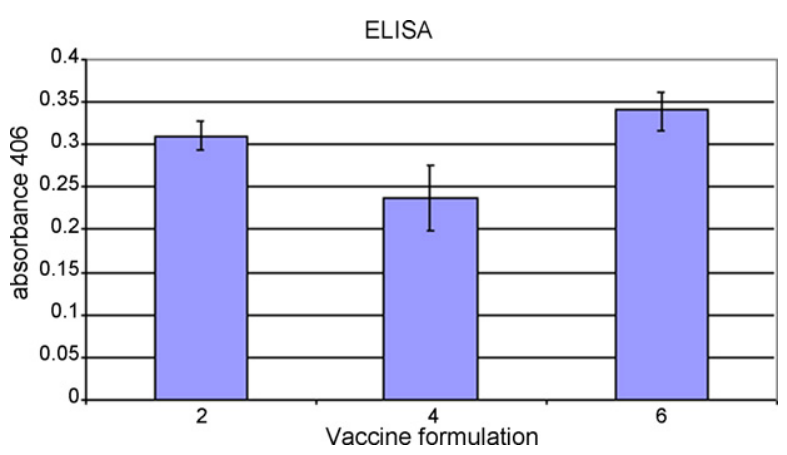

Fig. 1. IgG ELISA analysis of pre-challenge mice. Sera from three animals per group were used to generate average ELISA signal \pm S.E. Sera was diluted 1/4000. Vaccine peptides were conjugated to BSA prior to coating of ELISA plate. 


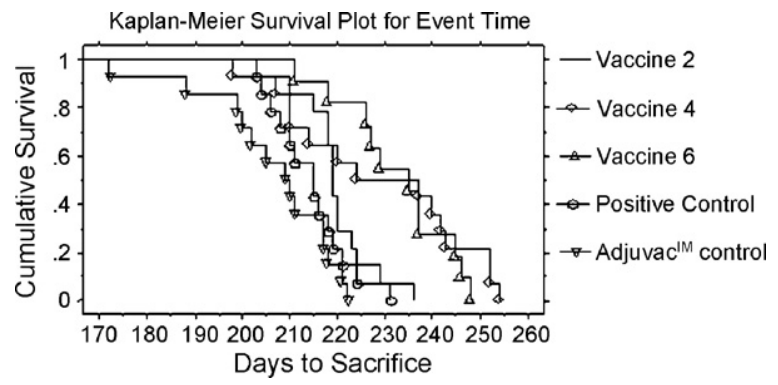

Fig. 2. Kaplan-Meier survivor curves. Vaccination with PrP peptides-BCP conjugates formulated in Adjuvac ${ }^{\mathrm{TM}}$ slows RML mouse-adapted scrapie disease progression relative to positive controls. The increase in incubation time is statistically relevant, $2, p=0.0041,4, p=0.0002$, and $6, p=0.0076$ (median survival compared Adjuvac $^{\mathrm{TM}}$ positive control).

prion dose of 1.5-2 logs (based on infectivity titrations of the RML strain provided by Sue Priola and Anne Ward from Rocky Mountain Laboratories). The apparent discrepancy between the lower $p$ value of vaccine 2 versus vaccine $6, p=0.004$ versus $p=0.0076$, respectively, can be accounted for in early sacrifices of several animals from the vaccine 6 experimental group. Interestingly, the Adjuvac ${ }^{\mathrm{TM}}$ challenge group appeared to display a slightly accelerated disease progression relative to the positive control (parametric ANOVA, $p=0.07$ ).

Most animals vaccinated with the vaccine 4 or vaccine 6 formulations showed a striking delay in onset of typical clinical symptoms. Few mice $(<5)$ from these groups displayed the typical kyphosis (hunched back), poor grooming, ataxic, or polydipsia behaviors present in the positive control groups from approximately days 200-214 p.i. After day 225 p.i., the majority of the animals in these two groups had begun to exhibit clinical symptoms that increased in severity and progressed in identical fashion to the positive control groups.

None of the vaccines produced obvious behavioral effects in any of the mice in the preclinical-phase of the disease, although detailed study of induced cognitive deficits due to vaccination were beyond the scope of this study. All animals in the study (expect negative control group) displayed the characteristic signs of mouse-adapted scrapie. The clinical signs and survival curves all conform to RML mouse-adapted scrapie strain for the dosage level used in this study, indicating that the challenge was successful. In addition, all end-stage clinical animals tested for PrPres by western blot and IHC showed accumulation of high levels of $\mathrm{PrP}^{\mathrm{res}}$ and spongiform neuronal pathology as shown in Fig. 3A and $\mathrm{B}$.

It must be noted that three animals from the same cage of the vaccine 4 treatment group died during the course of this study. Standard Western blot analysis of brains collected from these animals showed no high level PrPres accumulation indicative of terminal stage clinical scrapie and these animals were censored from the Kaplan-Meier and statistical analysis. Phosphotungesten Acid enrichment of $\mathrm{PrP}^{\text {res }}$ from $200 \mu \mathrm{l}$ of brain a $10 \%(\mathrm{w} / \mathrm{v} \%)$ homogenate and subsequent Western blot analysis did identify that $\mathrm{PrP}^{\mathrm{res}}$ was present at levels at least 50 -fold lower than a typical end-stage clinical animal (data not shown). The exact cause of these fatalities is not known.
(A)

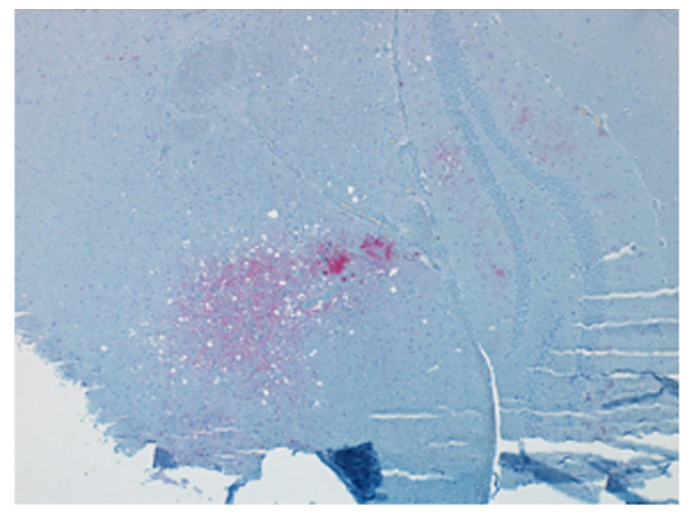

(B)

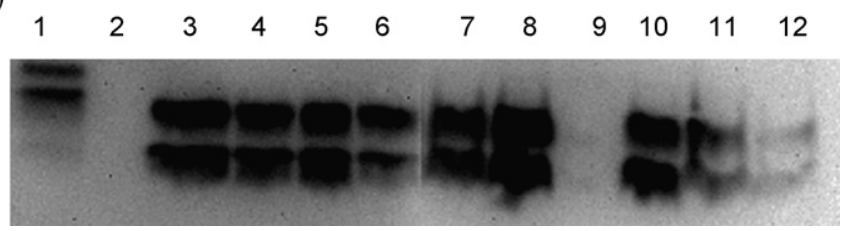

Fig. 3. (A) Immuno histochemistry of a positive control animal sacrificed in the terminal stage of the disease displays typical spongiform change and PrPres immuno staining. (B) Diagnostic western blot of two animals per group. $1=$ Brain homogenate-proteinase $\mathrm{K}(\mathrm{PK})$. Lane 2 =negative brain $+\mathrm{PK}$. Lanes 3 and $4=$ Adjuvac $^{\mathrm{TM}}$ control. Lanes 5 and $6=$ positive control. Lanes 7 and $8=$ group 2 . Lanes 9 and $10=$ group 4 . Lanes 11 and $12=$ group 6 . The animal in lane 9 died due to an undetermined illness at 152 days.

Although our active immunization approach did not result in total protection against challenge from $\mathrm{PrP}^{\mathrm{res}}$ containing brain homogenate, anti-prion effect as measured by increased days until sacrifice and delay in onset of clinical signs was observed in the vaccinated groups. These results are significant as immune tolerance to the self prion antigen was at least partially abrogated in this study as measured by relatively high ELISA values towards $\operatorname{PrP}^{\mathrm{c}}$ antigens for vaccines 2, 4, and 6 . The most comparable study by Schwarz et al. [12] required six $50 \mu \mathrm{g}$ peptide-KLH immunizations to generate antibody titers as measured by ELISA of 1/1500. Use of an adjuvant using $\mathrm{CpG}$ oligodeoxynucleotides to boost immune response to free prion peptides has been reported as a successful strategy to overcome immune tolerance [11]. A comparison of the antibody levels generated using the $\mathrm{CpG}$ adjuvant and free prion peptide approach to this study suggests that both higher antibody titers and less animal to animal immune response variability were obtained using BCP and the AdjuvacTM formulation described herein. $\mathrm{BCP}$ and Adjuvac ${ }^{\mathrm{TM}}$ adjuvant described here.

The titers generated by our active vaccination strategy were not strongly correlated to overall anti-prion protection; suggesting that in addition to overcoming the self-tolerance problem, a $\mathrm{PrP}^{\mathrm{c}}$ epitope must also be suitably identified that will generate antibodies that have high affinity to $\mathrm{PrP}^{\mathrm{res}}$. Vaccines 4 and 6 may present an example of this concept. The prion amino acid sequence of vaccine 6 , encompassing $\alpha$-helix 1 , includes the $\mathrm{N}$-terminal YYR motif shown to be solvent accessible in PrPres [10]. The amino acid sequence of vaccine 4 is also immediately $\mathrm{C}$-terminal to the second PrPres solvent exposed YYR motif. The proximity of the amino acid sequences used in vaccines 6 and 


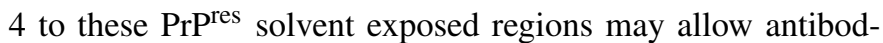
ies produced against the $\operatorname{PrP}^{\mathrm{c}}$ primary amino acid sequence to bind to epitopes that are present in both the $\mathrm{PrP}^{\mathrm{c}}$ and $\mathrm{PrP}^{\mathrm{res}}$ and induce T-cell mediated clearance of at least some level of $\mathrm{PrP}^{\mathrm{res}}$ infectivity.

While several groups have previously reported prion peptidecarrier protein strategies for inducing an active immune response to block the progression of TSEs, a fully successful study has yet to be reported. Schwarz et al. reported similar improvements in survival times as observed with our best performing vaccine constructs. However, direct comparisons are not totally relevant as the $\mathrm{PrP}^{\mathrm{res}}$ strain and route of challenge were different. Another study by Magri et al. using prion peptides conjugated to the traditional KLH carrier protein in the hamsters $263 \mathrm{~K}$ model system, reported no statistical significance between the non-immunized and vaccinated groups with respect to survival times due to high standard deviation and small sample size. It is interesting to note however that Magri et al. [5] did observe the longest median increase in survival time with a peptide that overlaps with the amino acid sequence of vaccine 6 , again highlighting the importance of the 141-179 region. Our study improves on these results by using a novel adjuvant and relatively new carrier protein to increase longevity in scrapie challenged mice.

The observation that the Adjuvac ${ }^{\mathrm{TM}}$ adjuvant appeared to slightly increase the progression of the disease was an unexpected corollary result of this vaccination study. An observation that appears to conflict with a published report of a therapeutic effect against prion disease progression by the administration of complete Freund's adjuvant alone [13]. The mechanism by which an adjuvant composed of $M$. avium subsp. avium could result in acceleration of $\mathrm{PrP}^{\text {res }}$ replication and/or neuroinvasion is unknown.

While we have demonstrated both an ability to overcome immune tolerance and generate a subsequent anti-prion effect by this vaccination method, a fully successful TSE vaccine was not achieved; at least as assessed by the high dose RML scrapie bolus challenge method used here. A better understanding of the structural features of $\mathrm{PrP}^{\text {res }}$ present on infectious prion particles and creation of vaccines the mimic PrPres structural features, will likely be needed to develop a truly efficacious CWD vaccine.

\section{Acknowledgments}

We would like to thank Dr. Gordon Gathright and the National Wildlife Research Center Animal Care staff for their assistance.

Funding: Funding support for this project was provided by the AHPIS Science Fellow program and USDA/APHIS/WS National Wildlife Research Center.

\section{References}

[1] A. Aguzzi, C.J. Sigurdson, Antiprion immunotherapy: to suppress or to stimulate? Nat. Rev. Immunol. 4 (2004) 725-736.

[2] J. Chabry, B. Caughey, B. Chesebro, Specific inhibition of in vitro formation of protease-resistant prion protein by synthetic peptides, J. Biol. Chem. 273 (1998) 13203-13207.

[3] P. De Ioannes, B. Moltedo, H. Oliva, R. Pacheco, F. Faunes, A.E. De Ioannes, M.I. Becker, Hemocyanin of the molluscan Concholepas concholepas exhibits an unusual heterodecameric array of subunits, J. Biol. Chem. 279 (2004) 26134-26142.

[4] M. Horiuchi, G.S. Baron, L.W. Xiong, B. Caughey, Inhibition of interactions and interconversions of prion protein isoforms by peptide fragments from the C-terminal folded domain, J. Biol. Chem. 276 (2001) 15489-15497.

[5] G. Magri, M. Clerici, P. Dall'Ara, M. Biasin, M. Caramelli, C. Casalone, M.L. Giannino, R. Longhi, L. Piacentini, S. Della Bella, P. Gazzuola, P.A. Martino, S. Della Bella, C. Pollera, M. Puricelli, F. Servida, I. Crescio, A. Boasso, W. Ponti, G. Poli, Decrease in pathology and progression of scrapie after immunisation with synthetic prion protein peptides in hamsters, Vaccine 23 (20052862-) 8.

[6] C.K. Mathiason, J.G. Powers, S.J. Dahmes, D.A. Osborn, K.V. Miller, R.J. Warren, G.L. Mason, S.A. Hays, J. Hayes-Klug, D.M. Seelig, M.A. Wild, L.L. Wolfe, T.R. Spraker, M.W. Miller, C.J. Sigurdson, G.C. Telling, E.A. Hoover, Infectious prions in the saliva and blood of deer with chronic wasting disease, Science 314 (2006) 133-136.

[7] M.W. Miller, E.S. Williams, Prion disease: horizontal prion transmission in mule deer, Nature 425 (2003) 35-36.

[8] M.W. Miller, E.S. Williams, N.T. Hobbs, L.L. Wolfe, Environmental sources of prion transmission in mule deer, Emerg. Infect. Dis. 10 (2004) $1003-1006$

[9] K. Pan, M. Baldwin, J. Nguyen, M. Gasset, A. Serban, D. Groth, I. Melhorn, Z. Huang, R.J. Fletterick, F.E. Cohen, S.B. Prusnier, Conversion of alpha-helices into beta-sheets features in the formation of the scrapie prion proteins, Proc. Natl. Acad. Sci. U.S.A. 90 (1993) 10962-10966.

[10] E. Paramithiotis, M. Pinard, T. Lawton, S. LaBoissiere, V.L. Leathers, W.Q. Zou, L.A. Estey, J. Lamontagne, M.T. Lehto, L.H. Kondejewski, G.P. Francoeur, M. Papadopoulos, A. Haghighat, S.J. Spatz, M. Head, R. Will, J. Ironside, K. O'Rourke, Q. Tonelli, H.C. Ledebur, A. Chakrabartty, N.R. Cashman, A prion protein epitope selective for the pathologically misfolded conformation, Nat. Med. 7 (2003) 893-899.

[11] M.B. Rosset, C. Ballerini, S. Gregoire, P. Metharom, C. Carnaud, P. Aucouturier, Breaking immune tolerance to the prion protein using prion protein peptides plus oligodeoxynucleotide-CpG in mice, J. Immunol. 172 (2004) 5168-5174.

[12] A. Schwarz, O. Kratke, M. Burwinkel, C. Riemer, J. Schultz, P. Henklein, T. Bamme, M. Baier, Immunisation with a synthetic prion protein-derived peptide prolongs survival times of mice orally exposed to the scrapie agent, Neurosci. Lett. 350 (2003) 187-189.

[13] Y. Tal, L. Souan, I.R. Cohen, Z. Meiner, A. Taraboulos, F. Mor, Complete Freund's adjuvant immunization prolongs survival in experimental prion disease in mice, J. Neurosci. Res. 71 (2003) 286290.

[14] A.R. White, P. Enever, M. Tayebi, R. Mushens, J. Linehan, S. Brandner, D. Anstee, J. Collinge, S. Hawke, Monoclonal antibodies inhibit prion replication and delay the development of prion disease, Nature 422 (2003) 80-83. 